\title{
Photosynthetic Activity in the Developing Cotyledon of Soybean Seeds
}

\author{
Toshio Sugimoto, Kiyoshi TanaKa, ${ }^{*}$ Michiko Momma \\ and Kyoko SAIO \\ National Food Research Institute, Ministry of Agriculture, Forestry, \\ and Fisheries, Tsukuba, Ibaraki 305, Japan \\ * Division of Environmental Biology, National Institute for Environmental Studies, \\ Tsukuba, Ibaraki 305, Japan
}

Received June 4, 1986

\begin{abstract}
We examined whether developing cotyledons of soybean seed had photosynthetic activities. The cotyledons evolved oxygen under illumination and the activity was inhibited by $3-\left(3^{\prime}, 4^{\prime}\right.$ dichlorophenyl)-1,1-dimethylurea. The rate of oxygen evolution decreased during the development of seeds; about $30 \mu \mathrm{mol} \mathrm{O}_{2} \cdot \mathrm{mg}$ chlorophyll ${ }^{-1} \cdot \mathrm{hr}^{-1}$ at the early developing stage and about $10 \mu \mathrm{mol} \mathrm{O}_{2} \cdot \mathrm{mg}$ chlorophyll ${ }^{-1} \cdot \mathrm{hr}^{-1}$ at the late developing stage. The rate of oxygen uptake remained at an almost constant level of $40 \mu \mathrm{mol} \mathrm{O} \mathrm{O}_{2} \cdot \mathrm{mg}$ chlorophyll ${ }^{-1} \cdot \mathrm{hr}^{-1}$ throughout the development. Photosynthetic ${ }^{14} \mathrm{CO}_{2}$-fixation by the cotyledon was observed. Ribulose bisphosphate carboxylase was immunochemically detected in the developing cotyledons. These results show that functional photosynthetic apparatus is present in the developing cotyledons of soybean seeds.
\end{abstract}

Photosynthesis in the organs related to reproduction is important in the yield of crops. In cereals, photosynthates from these organs, such as ears and flag leaves, contribute to the production of storage substances. ${ }^{1 \sim 3)}$ Pod walls of the crops photosynthesize. ${ }^{4 \sim 10)}$ The development of rape seeds proceeds after defoliation $^{7)}$; this is sustained mainly by the photosynthate of the pod. ${ }^{7,8)}$ Photosynthetic reassimilation of respiratory $\mathrm{CO}_{2}$ has been reported in the pod wall..$^{9,10)}$

We have reported ${ }^{11,12)}$ that amyloplasts in developing cotyledons of soybean seed have a lamella structure similar to that of chloroplasts in matured leaves. However, little is known about photosynthetic activities of the developing cotyledon of dicotyledonous seeds. We report here the occurence of photosynthetic activity in the developing soybean cotyledon, and its possible contribution to the crop production is discussed.

\section{MATERIALS AND METHODS}

Plant material. Soybean plants (Glycine max. cv. Enrei) were grown in pots at $25 / 20^{\circ} \mathrm{C}$ day/night and $70 \%$ humidity in an environment-controlled glass house under natural light. The pots were filled with $300 \mathrm{ml}$ of a $4: 2: 4: 1(\mathrm{v} / \mathrm{v})$ mixture of vermiculite, perlite, peat moss, and fine gravel which were supplied with a nutrient solution (1 g of Magamp K $\left(\mathrm{N}: \mathrm{P}_{2} \mathrm{O}_{5}: \mathrm{K}_{2} \mathrm{O}=6: 40: 5\right.$, W. R. Grace Co., Tennessee, USA)) and $3 \mathrm{~g}$ of magnesia lime twice a week. The fresh weights of seeds increased during development as previously observed. ${ }^{11)} \mathrm{A}$ seed which weighed $0.2 \mathrm{~g}$ was at the age of about $25 \mathrm{DAF}$ and one which weighed $0.6 \mathrm{~g}$ was about $50 \mathrm{DAF}$.

Uptake and evolution of oxygen by developing cotyledon. The cotyledon was cut latitudinally into slices of about $1 \mathrm{~mm}$ thickness after removing the pod wall and seed coat. Four slices were put into the well of an oxygen electrode (Rank Brothers, U.K.) with $2.5 \mathrm{ml}$ of $0.1 \mathrm{M}$ HEPES$\mathrm{NaOH}, \mathrm{pH}$ 7.6. The rate of oxygen uptake was measured in the dark at $25^{\circ} \mathrm{C}$ and then the reaction mixture was illuminated with a tungsten projector lamp about $5 \mathrm{~min}$ after the addition of the slices. The light intensity was $800 \mu \mathrm{E} \cdot \mathrm{m}^{-2} \cdot \mathrm{s}^{-1} \mathrm{PAR}$. The rate of $\mathrm{O}_{2}$ evolution was

Abbreviations: DCMU, 3-(3',4'-dichlorophenyl)-1,1-dimethylurea; PAR, photosynthetically active radiation; RUBPCase, ribulose bisphosphate carboxylase; PEPCase, phosphoenol pyruvate carboxylase; Chl, chlorophyll; DAF, days after flowering. 
calculated by subtracting the rate of oxygen uptake in the dark from the rate at about $5 \mathrm{~min}$ after illumination. The Chl content was measured spectrophotometrically. ${ }^{13)}$

Light-dependent ${ }^{14} \mathrm{CO}_{2}$-fixation of soybean cotyledon. Developing cotyledon (about 40 DAF) was cut into slices of about $1 \mathrm{~mm}$ thick, and $40 \mathrm{mg}$ of the slices (equivalent to $18 \mu \mathrm{g}$ of $\mathrm{Chl}$ ) was incubated in $0.5 \mathrm{ml}$ of $50 \mathrm{~mm}$ HEPES-NaOH, pH 7.6, containing $1 \mathrm{~mm} \mathrm{NaH}{ }^{14} \mathrm{CO}_{3}$ $(1.2 \mu \mathrm{Ci} / \mu \mathrm{mol})$ in the presence or absence of $0.2 \mathrm{~mm}$ DCMU for $20 \mathrm{~min}$ at $25^{\circ} \mathrm{C}$ under illumination. Two $\mathrm{ml}$ of methanol was added to the reaction mixture to end the reaction, and the slices were homogenized in the mixture. Then $0.1 \mathrm{ml}$ of $5 \%$ acetic acid was added to $0.2 \mathrm{ml}$ of the homogenate to remove the unincorporated carbon. The residual ${ }^{14} \mathrm{C}$ was measured by a Packard 3255 liquid scintillation counter.

Immunoassay of RUBPCase in the developing cotyledon. The immunoassay was done by the method of Ouchterlony. ${ }^{14)}$ The antibody against the large subunit of RUBPCase from maize leaves was a generous gift from Dr. Sugiyama of Nagoya University. Developing soybean seeds (1.34 g, $40 \mathrm{DAF})$, soybean leaves $(0.5 \mathrm{~g})$, or maize leaves $(0.5 \mathrm{~g})$ were homogenized in $2 \mathrm{ml}$ of $10 \mathrm{~mm}$ potassium phosphate, $\mathrm{pH} 7.2$, containing $0.15 \mathrm{M} \mathrm{NaCl}, 0.1 \%$ $\mathrm{NaN}_{3}$, and $10 \mathrm{~mm}$ dithiothreitol. After centrifugation at $10,000 \times g$ for $20 \mathrm{~min}, 10 \mu \mathrm{l}$ of the clear supernatant was put into each hole of the agarose gel, surrounding the center hole of anti-RUBPCase. The gel was stained with $0.5 \%$ amido black $10 \mathrm{~B}$ in $90 \%$ methanol and $10 \%$ acetic acid.

\section{RESULTS}

Oxygen evolution in developing soybean seed under illumination

Slices of the developing soybean cotyledon took up respiratory oxygen in the dark (Fig.

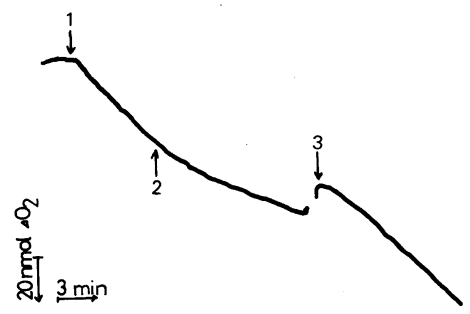

FIG. 1. Effects of Light and DCMU on Oxygen Exchange in Developing Soybean Cotyledons. (Age of the slices was about 40 DAF.)

1 , addition of the slices of the cotyledon; 2 , light on; 3 , addition of $0.1 \mathrm{~mm}$ DCMU.
1). When illuminated, the rate of oxygen uptake gradually decreased to reach a constant level after $5 \mathrm{~min}$ of light. The addition of $0.1 \mathrm{~mm}$.DCMU increased the rate of oxygen uptake to the original level in the dark. Because DCMU is a specific inhibitor of photosynthetic electron transport, ${ }^{15)}$ the lightdependent suppression of oxygen uptake is ascribed to photosynthetic oxygen evolution. Thus the results indicate that developing soybean cotyledons are photosynthetically competent.

\section{Changes in the rates of oxygen evolution and} uptake in cotyledons during development

Rates of oxygen exchange varied during the development of cotyledons as shown in Fig. 2. The rate of oxygen evolution at an early developing stage, where a cotyledon weighed

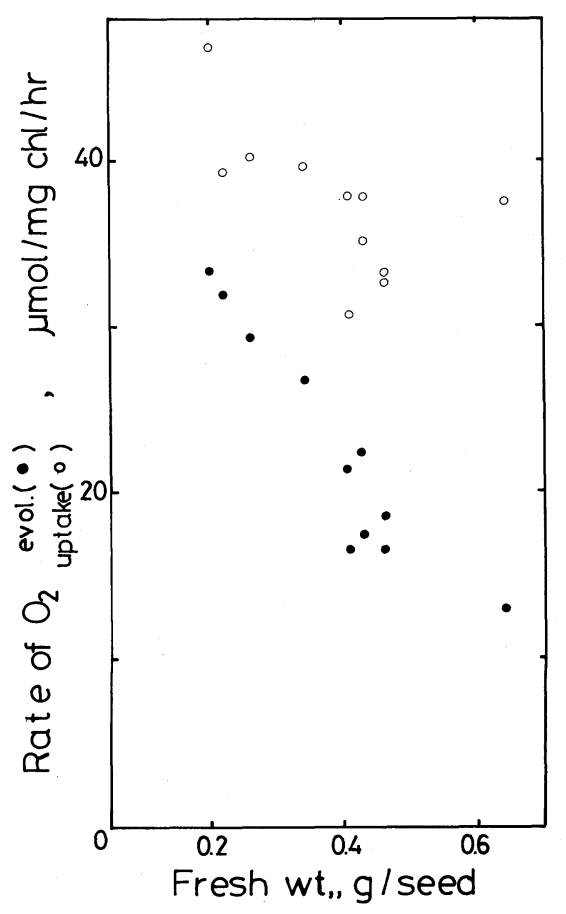

FIG. 2. Changes in Rates of Oxygen Uptake and Evolution of Developing Soybean Cotyledons during Maturation.

The rates were measured as described in the text. The seed maturation process is shown by weight increases. A seed which weighed $0.2 \mathrm{~g}$ was at the age of about $25 \mathrm{DAF}$ and one which weighed $0.6 \mathrm{~g}$ was about $50 \mathrm{DAF}$. 
$0.2 \mathrm{~g}$, was about $30 \mu \mathrm{mol} \mathrm{O} \cdot \mathrm{mg} \mathrm{Chl}^{-1} \cdot \mathrm{hr}^{-1}$ The rate decreased as the seed weight increased or maturation proceeded, and a cotyledon of $0.6 \mathrm{~g}$ at a late developing stage had an oxygen evolution rate of about $10 \mu \mathrm{mol} \mathrm{O}_{2} \cdot \mathrm{mg}$ $\mathrm{Chl}^{-1} \cdot \mathrm{hr}^{-1}$. The rate of oxygen uptake remained at an almost constant level of $40 \mu \mathrm{mol}$ $\mathrm{O}_{2} \cdot \mathrm{mg} \mathrm{Chl}^{-1} \cdot \mathrm{hr}^{-1}$ throughout the maturation.

\section{Light dependent $\mathrm{CO}_{2}$-fixation of developing soybean cotyledons}

Light-dependent $\mathrm{CO}_{2}$-fixation in slices of soybean cotyledon was also detected by measuring the incorporation of ${ }^{14} \mathrm{CO}_{2}$ into acid involatile products. The incorporation rate under illumination was $2.31 \mu \mathrm{mol} \mathrm{O}_{2} \cdot \mathrm{mg}$ $\mathrm{Chl}^{-1} \cdot \mathrm{hr}^{-1}$ as compared with a dark fixation rate of $0.46 \mu \mathrm{mol} \mathrm{O}{ }_{2} \cdot \mathrm{mg} \mathrm{Chl}^{-1} \cdot \mathrm{hr}^{-1}$. DCMU specifically reduced the light fixation. Rates of $\mathrm{CO}_{2}$-fixation were 0.83 and $0.37 \mu \mathrm{mol} \mathrm{O}_{2} \cdot \mathrm{mg}$

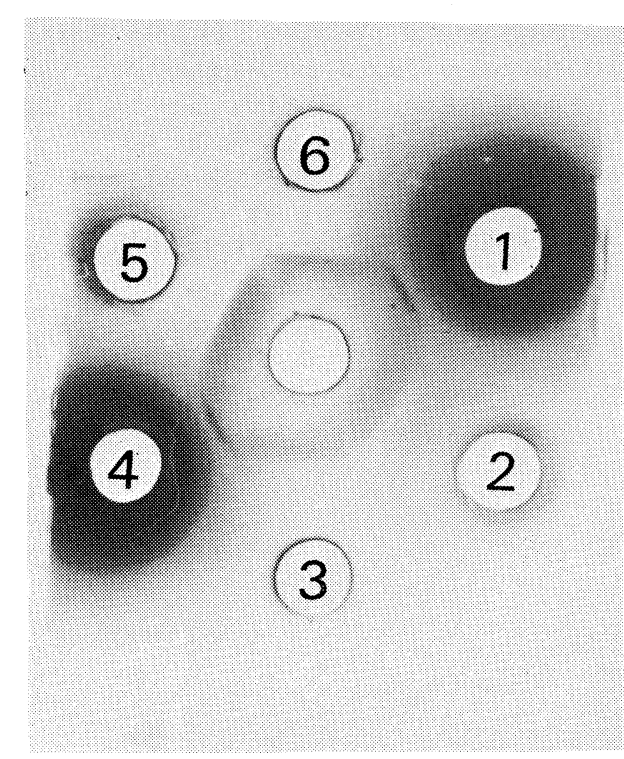

FIG. 3. Double Immunodiffusion Experiment Showing Precipitin Lines of RUBPCase in Developing Soybean Cotyledons.

The center well contained $10 \mu \mathrm{l}$ of antibody of the large subunit of RUBPCase.

Extracts from soybean cotyledons, maize leaves, and soybean leaves were placed in peripheral wells; 1 and 4 , soybean cotyledon; 2 and 5, maize leaves; 3 and 6 , soybean leaves.
$\mathrm{Chl}^{-1} \cdot \mathrm{hr}^{-1}$ in the light and dark, respectively, in the presence of $0.2 \mathrm{~mm}$ DCMU. The rate of $\mathrm{CO}_{2}$-fixation is considerably lower than that of $\mathrm{O}_{2}$ evolution. This may be ascribed to reassimilation of endogeneous $\mathrm{CO}_{2}$. At any event, the results show that soybean cotyledons can fix $\mathrm{CO}_{2}$ photosynthetically.

\section{Detection of RUBPCase protein in cotyledons of soybean seeds}

The third line of evidence for the occurence of photosynthetic apparatus in developing soybean cotyledons was obtained with an antibody against the large subunit of RUBPCase. The double radial immunodiffusion technique of Ouchterlony was used (Fig. 3). Immunoprecipitin lines were observed not only with extracts from maize and soybean leaves, which contain chloroplasts, but also with extracts from soybean cotyledons. This indicate that RUBPCase protein that is immunochemically the same as the enzyme from maize leaves is present in developing soybean cotyledons.

\section{DISCUSSION}

Photosynthesis by soybean seeds has been studied by Quebedeaux and Chollet $^{10)}$ and Sambo et al. ${ }^{16)}$ Sambo et al. measured the $\mathrm{CO}_{2}$ exchange of intact and deseeded soybean pods, and concluded that photosynthesis in the seeds and hulls refixed some $50 \sim 70 \%$ of the $\mathrm{CO}_{2}$ respired by these tissues. Quebedeaux and Chollet reported that gross photosynthesis of the pod was observed but the net photosynthesis was negligible. ${ }^{10)}$ It is important to measure the photosynthetic capacity of each part of the soybean pod, such as the pod wall, seed coat, and cotyledon to understand the role and function of photosynthesis in whole pod. Our work indicates that developing cotyledons of soybean seeds have a significant photosynthetic activity.

The finding that developing soybean cotyledons fix $\mathrm{CO}_{2}$ and evolve $\mathrm{O}_{2}$ under illumination indicates that the cotyledons of soybean seed had chloroplasts competent in photo- 
synthesis.

The rate of $\mathrm{O}_{2}$ evolution per $\mathrm{mg} \mathrm{Chl}$ was found to decrease during maturation. We suggest the following explanation for the change in the photosynthetic activity of the cotyledon during the maturation. At the early stage of development, sunlight penetrates inside the seeds and illuminates chloroplasts in the thin cotyledon. As the cotyledon gradually thickens and enlarges by the accumulation of storage substances during maturation, the intensity of light reaching chloroplasts is weakened, resulting in a gradually lose in the photosynthetic activity of chloroplasts inside the cotyledon.

Activities of RUBPCase and PEPCase have been observed in developing seeds of several crops. ${ }^{5,6,17,18)}$ Singal and Singh $^{17)}$ found a high activity of PEPCase in developing chickpea pods, and Shimotsubo et al. reported changes in the activities of these enzymes in rape seeds ${ }^{18)}$ during the maturation. It was reported that pod walls of soybean seeds had the two enzyme activities. ${ }^{10)}$ In this work, RUBPCase, an enzyme of the $\mathrm{CO}_{2}$-fixation cycle, was immunochemically detected in developing cotyledons of soybeans. Refixation of respiratory $\mathrm{CO}_{2}$ by these enzymes using photoenergy in the cotyledon may reduce the loss of carbon in the seed.

Acknowledgments. This study was supported by a Grant-in-Aid for Scientific Research from the Ministry of Agriculture, Forestry, and Fisheries of Japan (GEP-87II-3-1). We thank the members of the team of Green Ener- gy Project II-3 for helpful discussion.

\section{REFERENCES}

1) G. N. Thorne, Ann. Bot. N. S., 29, 317 (1965).

2) M. Moro-oka, K. Asada and Z. Kasai, J. Sci. Soil Manure, Japan, 43, 260 (1972).

3) L. T. Evans and H. M. Rason, Aust. J. Biol. Sci., 23, 245 (1970).

4) C. D. Elmore, Crop Sci., 13, 751 (1973).

5) Y. P. Luthra, I. S. Sheoran and R. Singh, Photosynthetica, 17, 210 (1983).

6) R. K. Chopra and S. K. Sinha, Photosynthetica, 16, 509 (1982).

7) Y. Hojyo, S. Kato and H. Kobayashi, Japanese J. Crop Sci., 41, 420 (1972).

8) S. Inanaga and K. Kumura, Japanese J. Crop Sci., 43, 261 (1974).

9) R. K. Crookston, J. O'Toole and J. L. Ozubun, Crop Sci., 14, 708 (1974).

10) B. Quebedeaux and R. Chollet, Plant Physiol., 55, 745 (1975).

11) K. Kondo, T. Sugimoto and K. Saio, Agric. Biol. Chem., 50, 581 (1986).

12) K. Saio, K. Kondo and T. Sugimoto, Food Microstructure, 4, 191 (1985).

13) G. Mackinney, J. Biol. Chem., 140, 315 (1941).

14) H. Nakamura "Jikken Seibutsugaku Koza," Vol. 14, ed. by S. Matsumura, T. Matsuda and Y. Katsura, Maruzen Co., Ltd., Tokyo, 1985, p. 78.

15) S. Kato, "Kogouseinyumon," Kyouritsu Shuppan Co., Ltd., Tokyo, 1973, p. 64.

16) E. Y. Sambo, J. Moorby and F. L. Milthorpe, Aust. J. Plant Physiol., 4, 713 (1977).

17) H. R. Singal and R. Singh, Plant Physiol., 80, 369 (1986).

18) K. Shimotsubo, Y. Hojyo and S. Kato, Japanese J. Crop Sci., 48 (extra issue 2), 81 (1979) 